\title{
IMMUNOCYTOCHEMICAL LOCALIZATION OF VASOACTIVE INTESTINAL POLYPEPTIDE-CONTAINING CELLS AND PROCESSES IN THE SUPRACHIASMATIC NUCLEUS OF THE RAT: LIGHT AND ELECTRON MICROSCOPIC ANALYSIS ${ }^{1}$
}

\author{
J. PATRICK CARD, ${ }^{*, 2}$ NICHOLAS BRECHA, $\ddagger$ HARVEY J. KARTEN, $\ddagger^{\S}$ AND ROBERT Y. MOORE*, \\ Departments of ${ }^{*}$ Neurology, $\ddagger$ Neurobiology and Behavior, and ${ }^{\S}$ Psychiatry and Behavioral Sciences, State University of New York at Stony \\ Brook, Stony Brook, New York, 11794
}

\begin{abstract}
The distribution of vasoactive intestinal polypeptide-like (VIP) immunoreactivity in neurons and processes within the suprachiasmatic nuclei (SCN) of the rat was investigated with light and electron microscopic immunocytochemical techniques. These studies utilized well characterized antisera directed to synthetic vasoactive intestinal polypeptide. Specificity was established by absorption of the antisera with synthetic vasoactive intestinal polypeptide. Neurons and dendrites exhibiting specific VIP immunoreactivity are concentrated in the ventral half of the nucleus, with the greatest concentration of immunoreactive perikarya occurring in the ventral SCN immediately adjacent to and within the optic chiasm (OC). Thin varicose axons containing VIP immunoreactivity are present throughout the SCN. A large number of immunoreactive axons leave the dorsal aspect of the SCN to reach the periventricular hypothalamic nucleus and continue dorsally to form an extensive plexus along the ventral border of the paraventricular hypothalamic nucleus. Other immunoreactive axons project upon the contralateral SCN via the OC. Ultrastructurally, VIP-containing neurons in the SCN are characterized by a spherical to slightly elongated soma and an invaginated nucleus that fills the majority of the cell body. In the soma, peroxidase reaction product is localized on the outer membrane of all cellular organelles. The reaction product of immunoreactive boutons is related primarily to vesicles, and some of these boutons establish axodendritic synaptic contacts in the SCN. The demonstration of VIP-containing neurons in the SCN provides further evidence that this nucleus is composed of a heterogeneous population of neurons which form distinct subfields within it.
\end{abstract}

Vasoactive intestinal polypeptide-like (VIP) immunoreactivity has been demonstrated in neurons of both the gastrointestinal tract and central nervous system in a number of investigations employing both immunohistochemical and radioimmunoassay procedures (for review, see Fahrenkrug, 1979). In addition to localization of VIP within defined populations of neuronal perikarya and processes, several studies have presented evidence implicating this peptide in synaptic function, either as a chemical transmitter or as a neuromodulator (for review, see

\footnotetext{
'This work was supported by United States Public Health Service Grant NS-16304 to R. Y. M., National Institutes of Health Grant EY02146 to H. J. K., and United States Public Health Service Postdoctoral Fellowship NS-06247 to J. P. C. We wish to express appreciation to Dr. Joseph N. Riley and Dr. Christine Gall for a critical reading of the manuscript and to Ms. Marianne Cilluffo and Ms. Chris Laverack for skilled technical assistance throughout the course of the study.

${ }^{2}$ To whom correspondence should be addressed at Department of Neurology, Health Sciences Center, T12, 020, State University of New York at Stony Brook, Stony Brook, NY 11794.
}

Fahrenkrug, 1979). These data have led to a continuing effort to define the location and projections of VIP immunoreactive neurons within the central nervous system.

A recent light microscopic immunohistochemical study of VIP localization in rat and mouse brain identified four major VIP systems in both species (Sims et al., 1980). These include an intracerebral cortical system, an amygdalofugal system, a hypothalamic system localized primarily within the suprachiasmatic nuclei, and a system originating in the midbrain central grey. The suprachiasmatic nucleus (SCN) of the hypothalamus was reported to contain a particularly dense concentration of VIP immunoreactive perikarya and processes. Immunoreactive neurons were located in the ventral half of the SCN, whereas immunoreactive processes, although present throughout the SCN, were concentrated in the dorsal and caudal aspects of the nucleus. The intent of the present investigation is to provide a systematic light and electron microscopic analysis of the organization of VIP. containing neurons and processes within the suprachias- 
matic nuclei of the rat. The reasons for the study are 3 fold. First, several investigations have shown that the SCN consists of neurons that can be separated into subpopulations on the basis of both fine structural (Suburo and Pellegrino de Iraldi, 1969; van den Pol, 1980; Moore et al., 1980) and immunocytochemical (Barry et al., 1974; Vandesande et al., 1975; Parsons et al., 1976; Alpert et al., 1976; Zimmerman and Robinson, 1976; Dierickx and Vandesande, 1977, 1979; Fuxe et al., 1977; van Leeuwen et al., 1978; Sofroniew and Weindl, 1978, 1980; Krisch, 1978; Sims et al., 1980; Peterson et al., 1980; Weind and Sofroniew, 1980) characteristics. These studies have shown that the distribution of the different neuronal subpopulations varies throughout both the rostrocaudal and mediolateral aspects of the nucleus. As a result, there is a need for a thorough analysis of the distribution of VIP-containing cells and processes in all portions of the nucleus. Second, there is no information on the ultrastructural characteristics of VIP neurons and axons in the SCN. It is therefore of interest to determine if VIP-positive immunoreactivity can be correlated with any of the morphologically distinct neuron and bouton classifications which have been demonstrated in the SCN. Finally, the established importance of the SCN in the regulation of circadian rhythmicity (cf., Moore, 1979, for review) makes any information on the organization of the SCN of potential value in determining the means by which the SCN participates in the regulation of circadian function.

\section{Materials and Methods}

\section{Antiserum}

Vasoactive intestinal polypeptide antisera (lot Nos. 7913 and 7916) were generously supplied by Dr. J. Walsh (Center for Ulcer Research and Education, University of California at Los Angeles). These antisera are directed to the $\mathrm{COOH}$-terminal of vasoactive intestinal polypeptide. Radioimmunoassay analysis has demonstrated that these antisera are inhibited completely by either vasoactive intestinal polypeptide or the 17- to 22-amino-acid fragment of VIP ( $J$. Walsh, personal communication). Histochemical tests of antibody specificity at the light microscopic level included preabsorbing the antiserum with $10 \mu \mathrm{M}$ synthetic vasoactive intestinal polypeptide, secretin, somatostatin, neurotensin, or vasopressin and substitution of these absorbed antisera for the unabsorbed antiserum. In addition, antibody specificity at the electron microscopic level was tested using antiserum preabsorbed with $10 \mu \mathrm{M}$ synthetic vasoactive intestinal polypeptide.

\section{Tissue preparation and immunocytochemical methods}

Light microscopy. Seventeen adult Sprague-Dawley rats ( 150 to $350 \mathrm{gm}$ ) of both sexes were used. Anesthetized rats (sodium pentobarbital, $40 \mathrm{mg} / \mathrm{kg}$ of body weight) were perfused with $50 \mathrm{ml}$ of $6 \%$ dextran followed immediately by 150 to $300 \mathrm{ml}$ of $4.0 \%$ paraformaldehyde in 0.1 $\mathrm{M}$ sodium phosphate buffer containing $0.1 \mathrm{M}$ lysine- $\mathrm{HCl}$ and $0.01 \mathrm{M}$ sodium periodate (PLP; McLean and Nakane, 1974). The brains were postfixed in PLP for 0.5 to $1.5 \mathrm{hr}$ and stored overnight at $4^{\circ} \mathrm{C}$ in $30 \%$ phosphate-buffered sucrose. Serial sections through the suprachiasmatic nuclei were cut at 25 to $30 \mu \mathrm{m}$ with a freezing microtome in the coronal (12 rats), sagittal (3 rats), or horizontal (2 rats) plane. Sections were collected and stored in $0.1 \mathrm{M}$ phosphate buffer at $4^{\circ} \mathrm{C}$ for 2 to $48 \mathrm{hr}$ prior to processing for immunohistochemical staining. In addition, 2 animals received an injection of colchicine into the lateral ventricle 2 days prior to sacrifice.

Sections processed according to the indirect immunofluorescent method of Coons (1958) were washed at room temperature in $0.1 \mathrm{M}$ phosphate buffer, $\mathrm{pH} 7.4$, and incubated in primary antisera (diluted to 1:1000 with $0.3 \%$ Triton $\mathrm{X}-100$ ) for $24 \mathrm{hr}$ at $4^{\circ} \mathrm{C}$. Tissue then was washed thoroughly in $0.1 \mathrm{M}$ phosphate buffer and placed in fluorescein isothiocyanate (FITC) conjugated to goat anti-rabbit globulin (Miles) diluted to $1: 100$ with $0.3 \%$ Triton X-100 for $30 \mathrm{~min}$ at room temperature. Subsequently, sections were washed in several changes of 0.1 M phosphate buffer, mounted on gelatin-coated slides, and coverslipped with a glycerin/carbonate mixture. Sections then were analyzed and photographed using a Leitz Orthoplan photomicroscope.

Tissue prepared by the indirect immunoperoxidase technique of Sternberger (1979) was processed as follows. Following a 10-min phosphate buffer wash at room temperature (with or without $10 \%$ normal goat serum), sections were incubated in primary antisera (diluted to 1: 1000 with $0.3 \%$ Triton $\mathrm{X}-100$ ) for 24 to $48 \mathrm{hr}$ at $4^{\circ} \mathrm{C}$. Sections were washed thoroughly in $0.1 \mathrm{M}$ phosphate buffer and transferred to goat anti-rabbit IgG (diluted to 1:50 with $0.3 \%$ Triton $X-100$ ) for 30 to 45 min at room temperature. In some instances, $1 \%$ normal goat serum was added to the IgG. Excess IgG was washed from the tissue by several changes of phosphate buffer and transferred to rabbit peroxidase-antiperoxidase (PAP; Cappel) diluted in $0.3 \%$ Triton X-100 (1:50 to $1: 150)$ for 30 to 45 $\mathrm{min}$ at room temperature with agitation. After washing in several changes of phosphate buffer, sections were incubated in diaminobenzidine (DAB; $33 \mathrm{mg} / 100 \mathrm{ml}$ ) in $0.1 \mathrm{M}$ cacodylate buffer ( $\mathrm{pH} 7.2$ ), $0.1 \mathrm{M}$ phosphate buffer (pH 7.2), or $0.05 \mathrm{M}$ Tris/saline buffer for $10 \mathrm{~min}$. In some instances, tissue was washed in $0.5 \%$ cobalt chloride in $0.1 \mathrm{~m}$ Tris- $\mathrm{HCl}$ (pH 7.6) prior to DAB incubation (Adams, 1977). Following the DAB preincubation, $\mathrm{H}_{2} \mathrm{O}_{2}$ was added to the DAB solution (final concentration, $0.01 \%$ ) with agitation for an additional 2 to $10 \mathrm{~min}$. Sections were washed in buffer, mounted on gelatin-coated slides, dehydrated in ethanol, cleared in xylene, and coverslipped with Permount. The DAB reaction product in selected sections was intensified by incubating reacted tissue in 0.1 to $0.2 \%$ osmium tetroxide $\left(\mathrm{OsO}_{4}\right)$ for 15 to $60 \mathrm{sec}$ prior to clearing and coverslipping.

Electron microscopy. With only slight modification, tissue prepared for electron microscopic immunocytochemistry was processed according to the procedures of Pickel et al. (1980). Rats were perfused with physiological saline followed by $4 \%$ paraformaldehyde, $0.2 \%$ glutaraldehyde in $0.1 \mathrm{M}$ phosphate buffer, $\mathrm{pH}$ 7.6. The brain was removed and postfixed for $1.5 \mathrm{hr}$ at $4^{\circ} \mathrm{C}$, after which, 30to $50-\mu \mathrm{m}$ serial sections through the SCN were cut in the coronal or sagittal planes with a Vibratome (Oxford Instruments). Sections were collected in $0.1 \mathrm{M}$ phosphate 
buffer, washed for $30 \mathrm{~min}$ in two changes of $0.5 \mathrm{~m}$ Tris/ saline buffer, and incubated in the primary antisera (diluted to $1: 1000$ with $0.5 \mathrm{M}$ Tris/saline buffer) for 24 to 48 $\mathrm{hr}$ at $4^{\circ} \mathrm{C}$. Sections then were washed for $30 \mathrm{~min}$ in several changes of the Tris/saline buffer prior to and following a 30 -min incubation in IgG (1:50) at room temperature. After the last buffer wash, sections were placed in peroxidase-antiperoxidase $(1: 50)$ for $30 \mathrm{~min}$ at room temperature with agitation. Tissue then was washed twice in Tris/saline buffer and reacted in a $0.5 \%$ solution of DAB in $0.1 \mathrm{~m}$ phosphate buffer containing $0.1 \% \mathrm{H}_{2} \mathrm{O}_{2}$. Following the DAB reaction, tissue was washed in several changes of phosphate buffer and placed in a $2.0 \%$ solution of $\mathrm{OsO}_{4}$ in $0.1 \mathrm{M}$ phosphate buffer $(\mathrm{pH}$ 7.2) containing $1.5 \%$ potassium ferricyanide. The potassium ferricyanide was included in the $\mathrm{OsO}_{4}$ since it improves the preservation of membranes in aldehyde-fixed material (Langford and Coggeshall, 1980). Following osmification for $1 \mathrm{hr}$, sections were washed twice in phosphate buffer, dehydrated in a graded ethanol series, passed through two changes of propylene oxide, and infiltrated and embedded in Epon-Araldite plastic resin.
Thin sections of each Vibratome section were cut with a Reichert Ultracut ultramicrotome (American Optical), collected on Formvar-coated slot grids, and examined unstained with a JEOL $100 \mathrm{CX}$ transmission electron microscope. In order to determine areas of the SCN present in each section, $0.5-\mu \mathrm{m}$-thick sections cut immediately adjacent to the thin sections were collected and stained with toluidine blue.

\section{Results}

Immunoreactivity to VIP antisera is observed in neuronal perikarya and dendrites located in the ventral half of the suprachiasmatic nuclei (SCN) and in varicose axons throughout the nucleus. The specificity of the immunoreactivity to VIP was verified by the loss of immunoreactive staining in sections incubated in VIP antiserum preabsorbed with $10 \mu \mathrm{M}$ synthetic vasoactive intestinal polypeptide. Similarly, VIP immunoreactive staining does not appear to be due to cross-reactivity with somatostatin, neurotensin, vasopressin, or secretin since incubation of tissue in antiserum preabsorbed with $10 \mu \mathrm{M}$ concentrations of each of these peptides did not

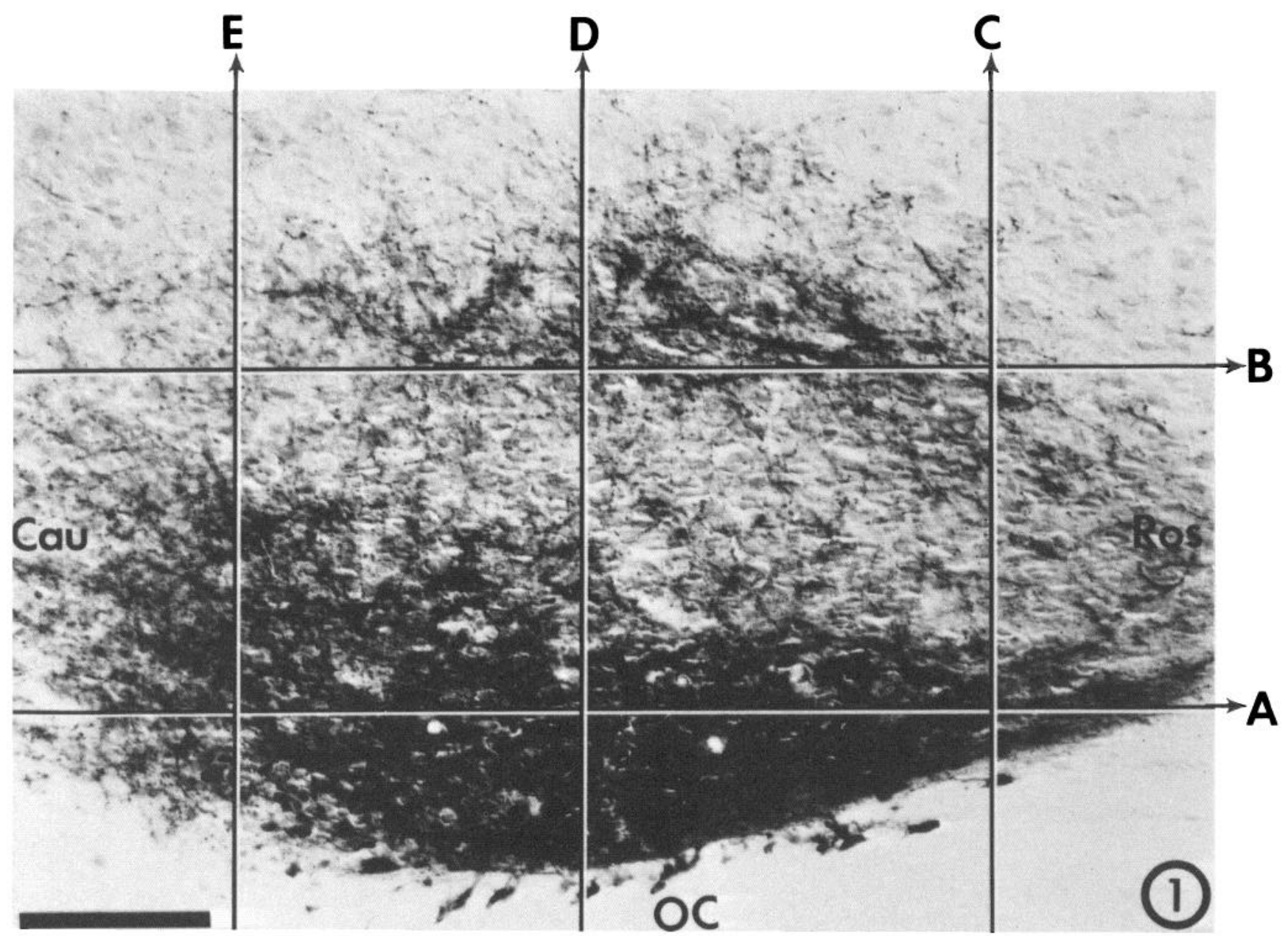

Figure 1. A parasagittal section through the suprachiasmatic nucleus of the rat illustrating the distribution of VIP-containing cells and processes and the approximate planes $(A$ to $E)$ of the sections illustrated in Figures 2 through 6 . Immunoreactive perikarya are concentrated in the ventral third of the SCN, except at the extreme rostral and caudal aspects of the nucleus. Positively stained perikarya also are situated entirely within the optic chiasm throughout the rostrocaudal extent of the SCN/OC interface. VIP-containing beaded axons are present throughout the nucleus but arborize most extensively in the caudal and dorsal portions of the SCN. Ros, rostral; Cau, caudal; marker bar $=100 \mu \mathrm{m}$. 
eliminate specific staining. The distribution of immunoreactive staining was identical in tissue prepared by both the FITC and PAP procedures and colchicine pretreatment did not reveal any immunoreactive perikarya other than those described below. Cobalt and osmium treatment of tissues intensified the reaction product, often allowing for visualization of more of the dendritic tree of immunoreactive neurons.

\section{Light microscopy}

Perikarya. Examination of coronal, sagittal, and horizontal sections through the SCN demonstrated that neurons and dendrites exhibiting VIP immunoreactivity are concentrated within the ventral half of the SCN with the exception of the rostral and caudal poles of the nucleus (Figs. 1, 2, and 4 to 7). This is best illustrated in parasagittal sections (Fig. 1) in which immunoreactive perikarya are aggregated within the ventral portion of the middle two-thirds of the nucleus. Immunoreactivity in the remainder of the SCN (rostral, caudal, and dorsal aspects) is restricted to varicose axonal profiles (Figs. 1, 3, 4, and 6). The greatest concentration of neurons exhibiting immunoreactivity is observed in the area of the SCN immediately adjacent to the optic chiasm (OC). In this region, which encompasses approximately the ventral third of the SCN, immunoreactive perikarya are packed so densely that it is difficult to discern whether unstained neurons are present (Figs. 2 and 7). The dense aggregation of immunoreactive neuronal perikarya extends throughout the entire mediolateral extent of the SCN/ OC interface (Fig. 5). Furthermore, while the greatest concentration of VIP neurons is immediately adjacent to the OC, scattered immunoreactive perikarya occur throughout the ventral half of the SCN. No immunoreactive perikarya are evident within either the dorsomedial or dorsolateral quadrants of the SCN.

VIP-containing neurons in the area of the SCN are not confined to the classical anatomical boundaries of this nucleus. Immunoreactive neurons totally isolated within the confines of the $\mathrm{OC}$ are consistently observed in large numbers along the rostrocaudal and mediolateral extent of the SCN/OC interface (Figs. 1, 4, 5, and 7). These intrachiasmatic neurons generally give rise to one or more dendrites which are preferentially oriented dorsally toward the SCN, often extending into the ventral aspect of the nucleus. Conversely, immunoreactive neurons immediately adjacent to the $\mathrm{OC}$, but within the boundaries of the SCN, frequently give rise to both dendrites and varicose axons which course ventrally into the OC (Figs. 7 and 8 ).
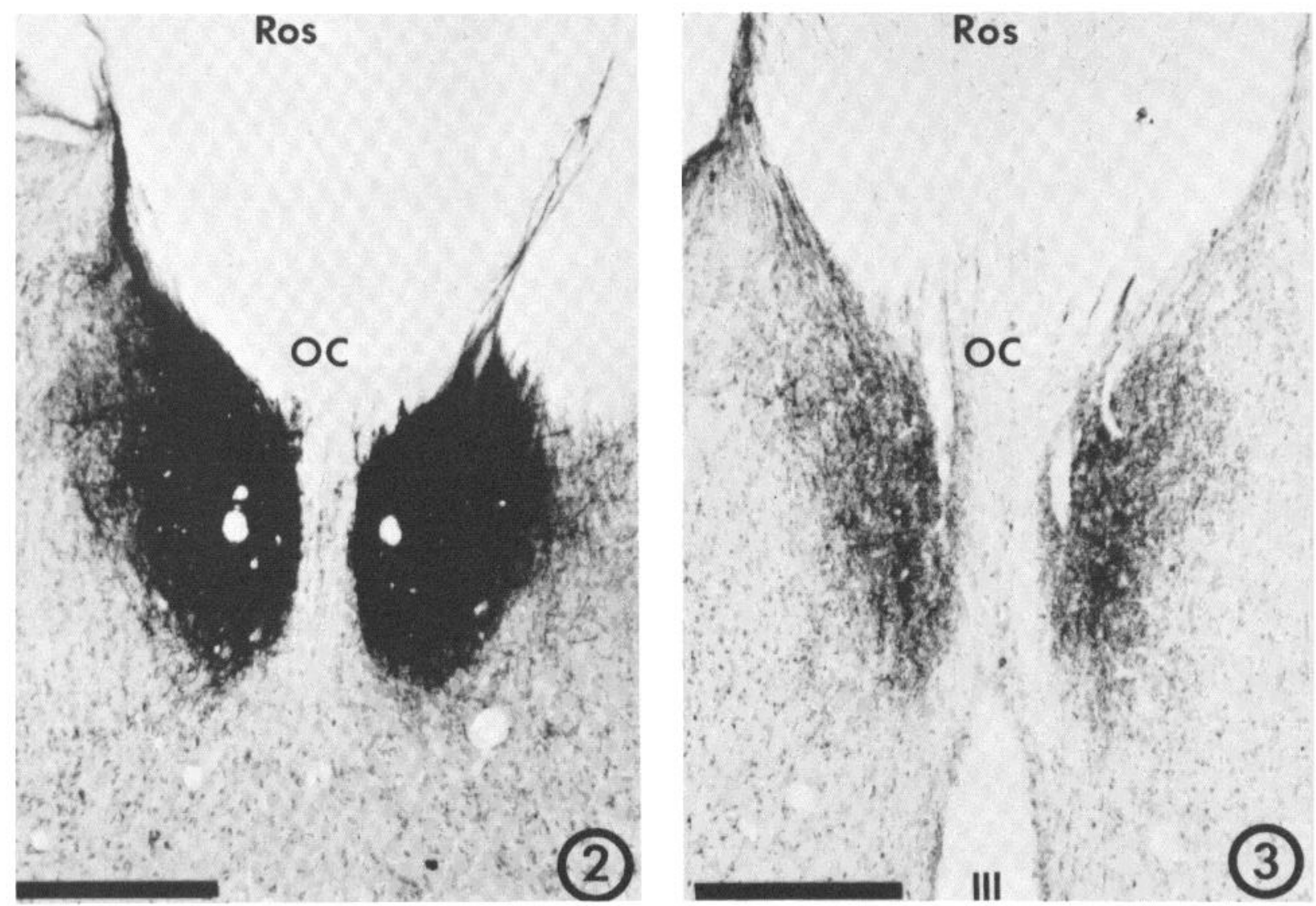

Figures 2 and 3. The distribution of VIP-positive cells and processes as seen in horizontal sections is illustrated. The approximate plane of section for each of the photomicrographs is indicated in Figure 1 (plane $A$ for Fig. 2 and plane B for Fig. 3). Immunoreactive perikarya are packed densely in the ventral SCN throughout the mediolateral extent of the nucleus (Fig. 2). In the dorsal portion of the SCN, immunoreactivity is found only in varicose axons (Fig. 3). III, third ventricle; Ros, rostral; marker $b a r=500 \mu \mathrm{m}$. 

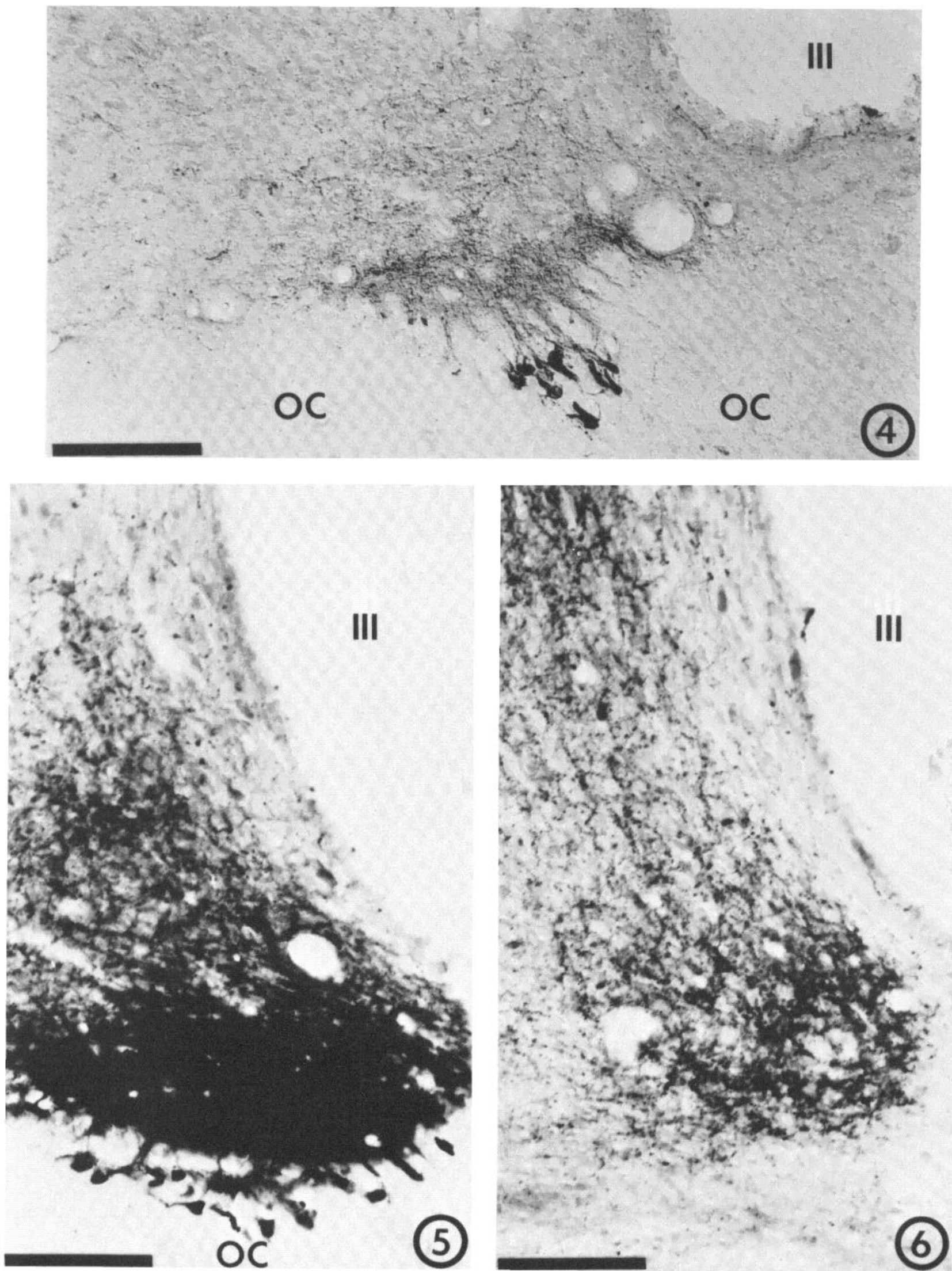

Figures 4 to 6 . Photomicrographs of coronal sections through the SCN corresponding to the planes designated $C, D$, and $E$ in Figure 1. In the most rostral section (Fig. 4), immunoreactivity is relegated to beaded axons within the nucleus, while positively stained perikarya are found only in the optic chiasm. The intermediate portion of the SCN (Fig. 5) is characterized by a dense aggregation of immunoreactive perikarya in the ventral third of the SCN and beaded immunoreactive axons in the dorsal portion of the nucleus. Immunoreactive perikarya also are present in the optic chiasm throughout the mediolateral extent of the SCN/OC interface. The caudal SCN (Fig. 6), which lies dorsal to the crossing fibers of the caudal OC, exhibits only scattered immunoreactive perikarya and an extensive plexus of VIP axons which pass dorsally into the periventricular hypothalamic nucleus. III, third ventricle; marker bars $=100 \mu \mathrm{m}$. 
Processes. Thin varicose processes demonstrating VIP immunoreactivity are present throughout the entire extent of the SCN but appear to be most prevalent within the dorsal and caudal portions of the nucleus (Figs. 1, 3, 5 , and 6 ). It is difficult to determine the fiber density in the ventral portion of the SCN at the light microscopic level due to the large number and close proximity of intensely immunoreactive SCN neurons (Fig. 7). Nevertheless, light and electron microscopic (see description below) analyses reveal numerous beaded immunoreactive axons within the ventral SCN which extend into the remaining areas of the nucleus. In parasagittal sections through the SCN, many of these axons arborize within the caudal and dorsal aspects of the nucleus (Fig. 1). However, a large number of immunoreactive axons leave the dorsal aspect of the SCN and pass into the periventricular hypothalamic nucleus and the immediately adjacent anterior hypothalamic area (Figs. 5 and 6). These axons, which exhibit varicosities throughout their full extent, continue dorsally to form an extensive plexus which arborizes along the ventral border of the paraventricular nucleus (PVH; Fig. 9). Scattered immunoreactive axons course into the PVH. Other immunoreactive axons leave the medial aspect of the SCN and traverse the OC to pass into the contralateral SCN (Fig. 8).

\section{Electron microscopy}

The intensity of VIP immunoreactive staining exhibited in SCN neurons and processes is dependent upon the proximity of the ultrathin section to the tissue sample surface. Sections taken from the most superficial portion of the tissue contain immunoreactive profiles which exhibit such dense reaction product that it is often difficult to discern any of the fine structural characteristics of the profile. In contrast, sections taken deeper into the tissue block exhibit progressively less intense immunoreactive staining. Virtually no reaction product was evident in sections taken deeper than $10 \mu \mathrm{m}$ from the tissue sample surface. The majority of the analysis in the present study was carried out on sections 2 to $5 \mu \mathrm{m}$ from the sample surface. Such samples contained sufficient peroxidase reaction product within stained profiles to ensure identification of VIP-containing neurons and processes, but the reaction product is not so dense as to obscure the ultrastructural characteristics of the labeled profile or its relationship to surrounding structures.

Perikarya. Positively stained neuronal perikarya exhibit a spherical to slightly elongated shape (Fig. 10). The long axis of the cell is approximately $12 \mu \mathrm{m}$ in length, while the short axis of the cell is approximately $7.5 \mu \mathrm{m}$

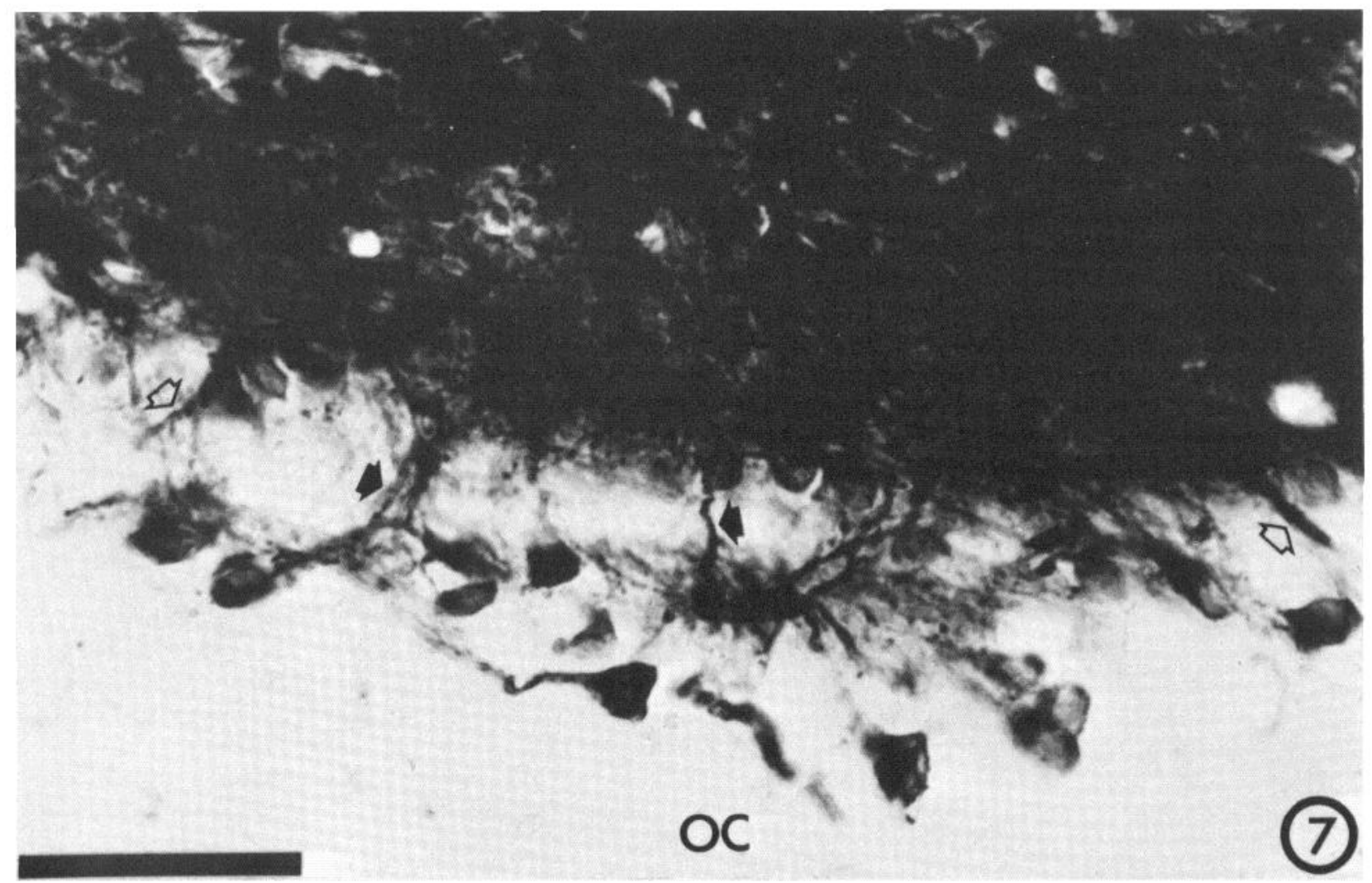

Figure 7. Dense labeling of neurons and processes is typically found throughout the ventral aspect of the intermediate twothirds of the suprachiasmatic nucleus in the rostrocaudal axis. In this high magnification view of the ventral SCN illustrated in Figure 5, immunoreactivity is displayed by virtually every neuron in the area immediately adjacent to the optic chiasm. Some of the SCN neurons send processes into the OC (open arrows), while other immunoreactive intrachiasmatic neurons give rise to processes which pass dorsally into the SCN (solid arrows). Marker bar $=50 \mu \mathrm{m}$. 


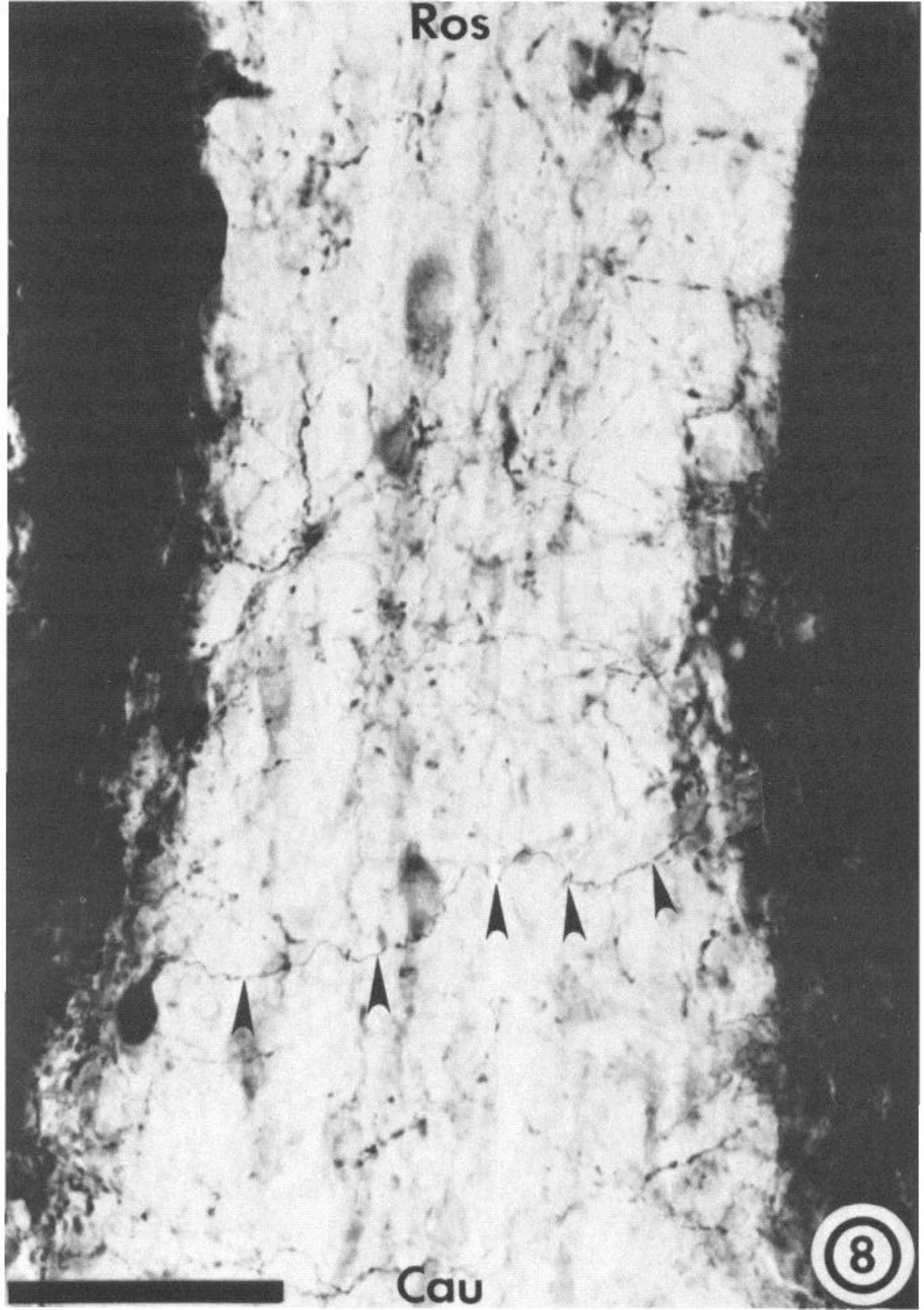

Figure 8. Immunoreactive beaded axons originating from neurons of one suprachiasmatic nucleus traverse the optic chiasm (arrowheads) to pass into the contralateral SCN. This is a photomontage of the area of OC between the suprachiasmatic nuclei shown in Figure 2. Ros, rostral; cau, caudal; marker bar $=50 \mu \mathrm{m}$.

long. The cell nucleus usually is placed centrally within the soma and often exhibits a number of finger-like invaginations. The cytoplasm of the neuron is characterized by a light organelle-rich matrix. Peroxidase reaction product is localized on the outer membrane of all of the cellular organelles but is particularly evident on external membranes of Golgi cisternae, on the outer membranes of vesicles, and on the external mitochondrial membrane (Figs. 10 and 11). Other organelles, such as cisternae of rough endoplasmic reticulum and microtubules, also exhibit reaction product; however, the intensity of the staining of these and other organelles is much more dependent upon the proximity of the thin section to the tissue sample surface. No reaction product was apparent free within the cytoplasm.

Immunoreactive neurons within the optic chiasm share the same ultrastructural and staining characteristics as neurons located within the nucleus proper (Fig. 12). These cells often reside within a pocket of intrachiasmatic neuropil which also contains positively stained axons and dendrites. Often, one or more dendrites extend dorsally from the soma of these cells toward the SCN. 


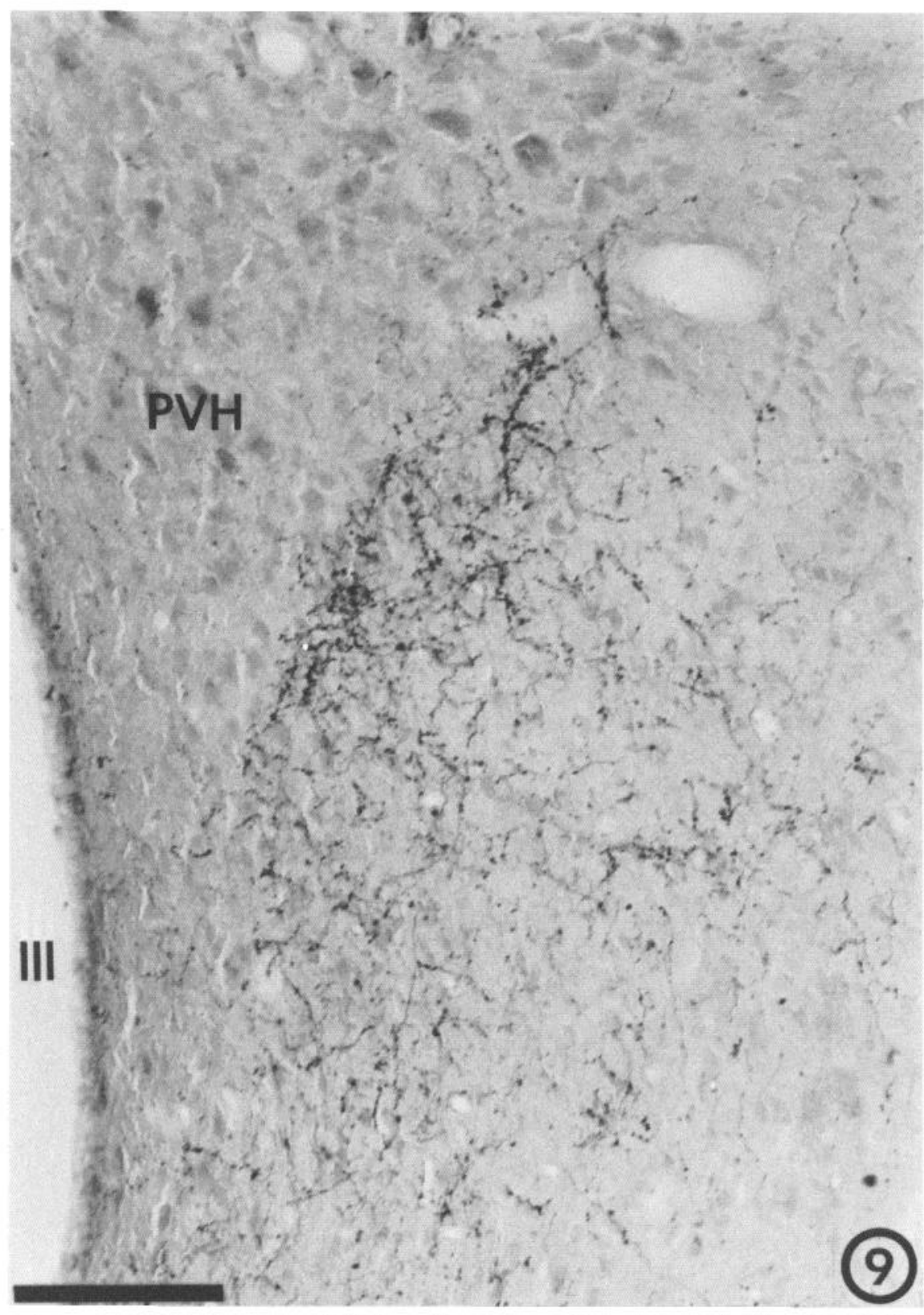

Figure 9. Arborization of VIP-positive axons along the ventral border of the paraventricular hypothalamic nucleus is illustrated. Only scattered processes pass into the PVH. III, third ventricle; marker bar $=100 \mu \mathrm{m}$.

As stated in the light microscopic description, VIP-positive intrachiasmatic neurons are present throughout the rostrocaudal and mediolateral extents of the SCN/OC interface.

Processes. Peroxidase reaction product is observed within dendrites, vesicle-filled boutons, and intervaricose segments of axons throughout the SCN (Figs. 13 and 14). No attempt was made to determine variations in fiber density in different parts of the nucleus due to the variability of immunoreactive staining in tissue prepared for electron microscopic analysis. Within intervaricose segments of axons and in dendrites, reaction product is observed upon microtubules and external mitochondrial membrane. Immunoreactive boutons characteristically exhibit a clear axoplasm containing mitochondria and varying numbers of lucent spherical vesicles distributed throughout the ending (Fig. 13). Dense core vesicles are observed only occasionally in these terminals. Within labeled boutons, reaction product is localized on the outer surface of the small spherical vesicles and mitochondria. When present in labeled terminals, dense core vesicles exhibit an enhanced density of the core.

Positively stained boutons are observed most often in apposition to dendrites within the SCN. In some instances, asymmetric synaptic contacts are present between dendrites and labeled boutons (Fig. 13). Similarly, immunoreactive dendrites characteristically exhibit sites of synaptic specialization with unlabeled boutons (Fig. 

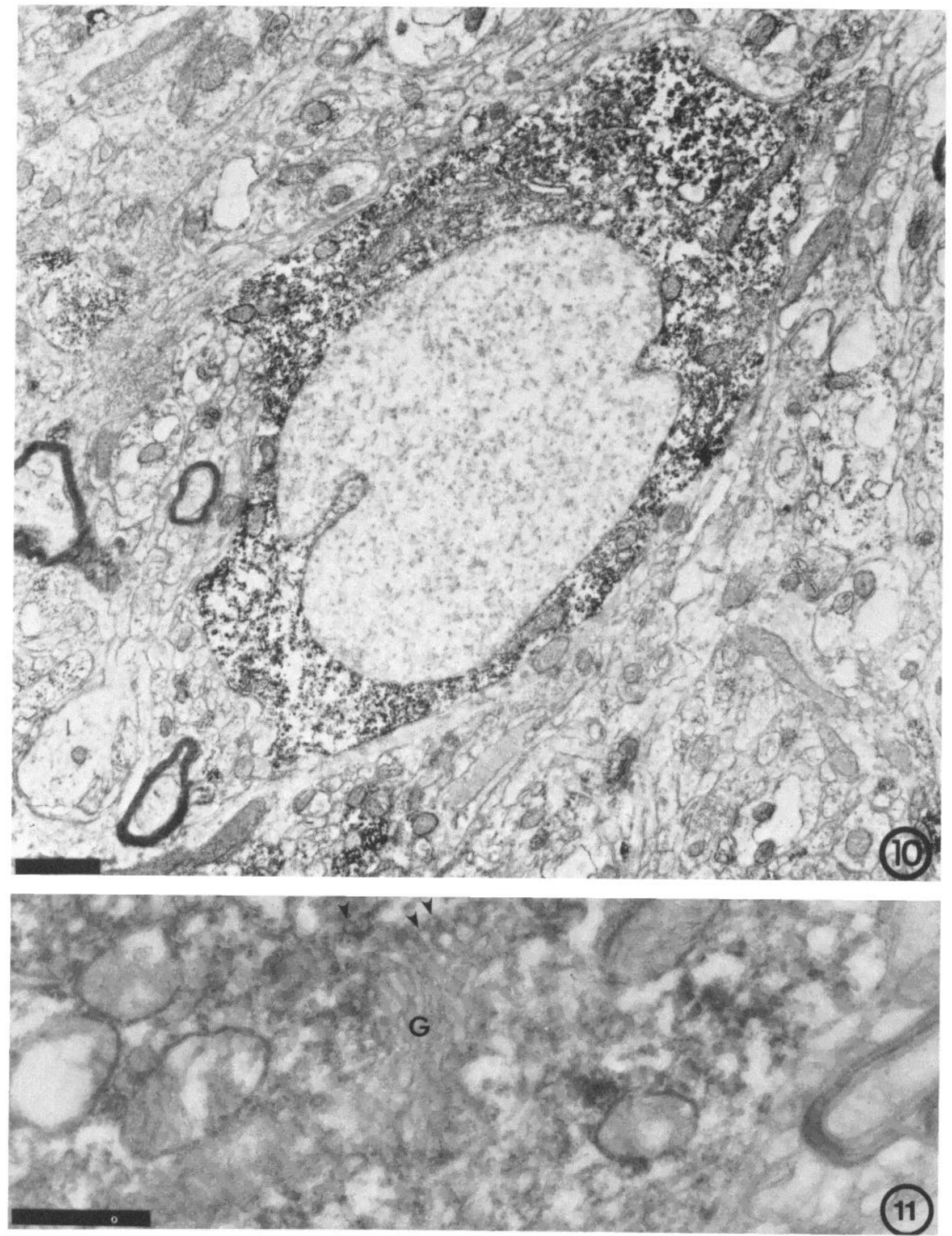

Figure 10. Transmission electron micrograph illustrating the fine structure typical of that seen in immunoreactive suprachiasmatic neurons in the ventral portion of the SCN. Immunoreactive neurons exhibit a spherical to slightly elongated soma and a light organelle-rich cytoplasm. The cell nucleus is usually placed centrally within the soma and is characterized by finger-like invaginations. Marker bar $=1.0 \mu \mathrm{m}$.

Figure 11. The intracellular distribution of peroxidase reaction product within immunoreactive SCN neurons is illustrated. The reaction product is characteristically found on the external membrane of all cellular organelles but is particularly prominent on the external mitochondrial membrane and vesicles (arrowheads) associated with Golgi cisternae $(G)$. Marker bar $=0.5 \mu$ m. 


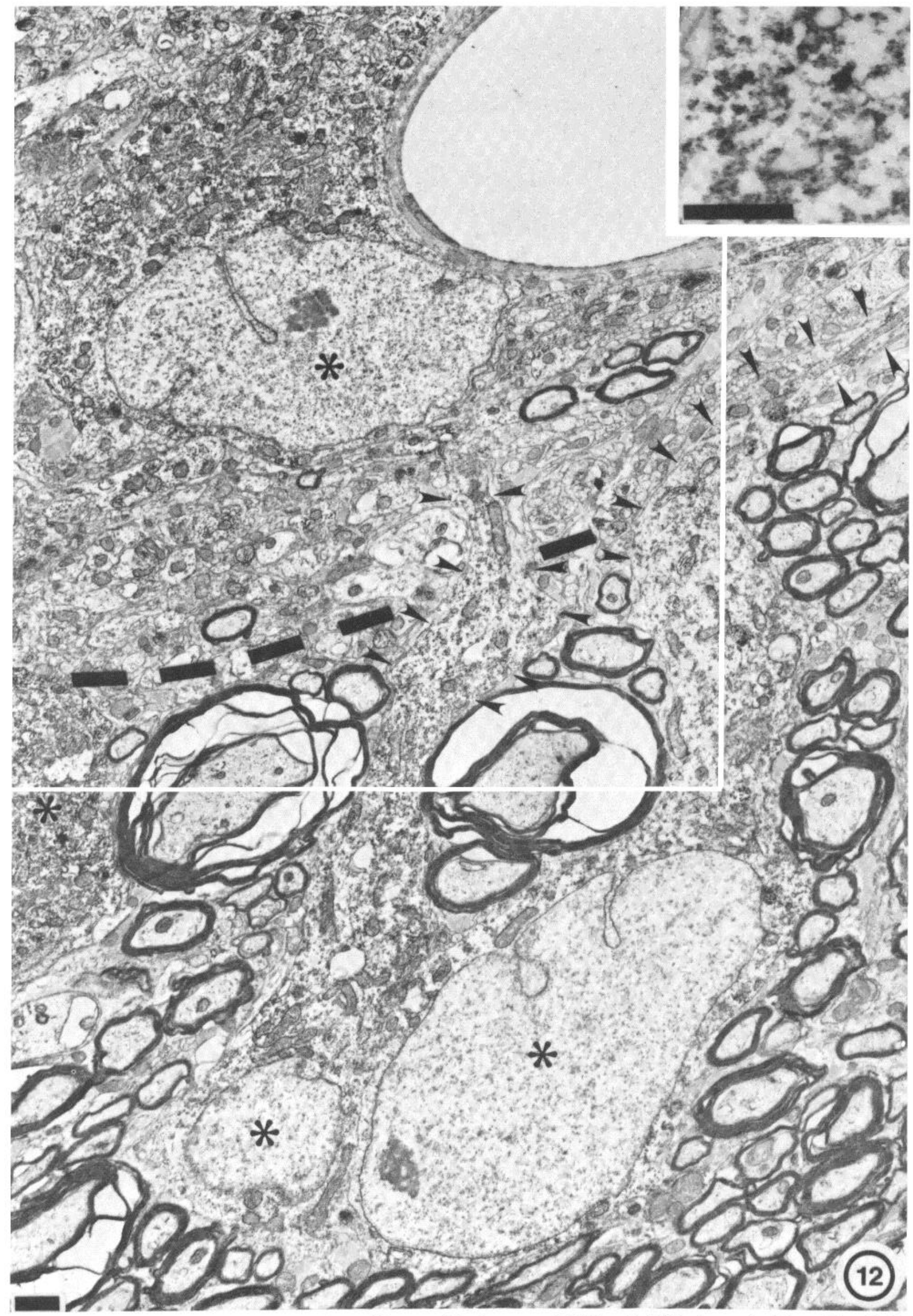

Figure 12. Discretely labeled VIP neurons (*) are illustrated in the ventral SCN and within the optic chiasm. The dashed line indicates the SCN/OC interface. The two VIP-containing intrachiasmatic neurons give rise to dendrites (arrowheads) which course dorsally into the SCN. Another neuron in the ventral portion of the SCN is closely apposed to a small capillary. The inset illustrates peroxidase localization in the cells at higher magnification. Marker bar on main figure $=1 \mu \mathrm{m} ;$ marker bar on inset $=0.5 \mu \mathrm{m}$ 

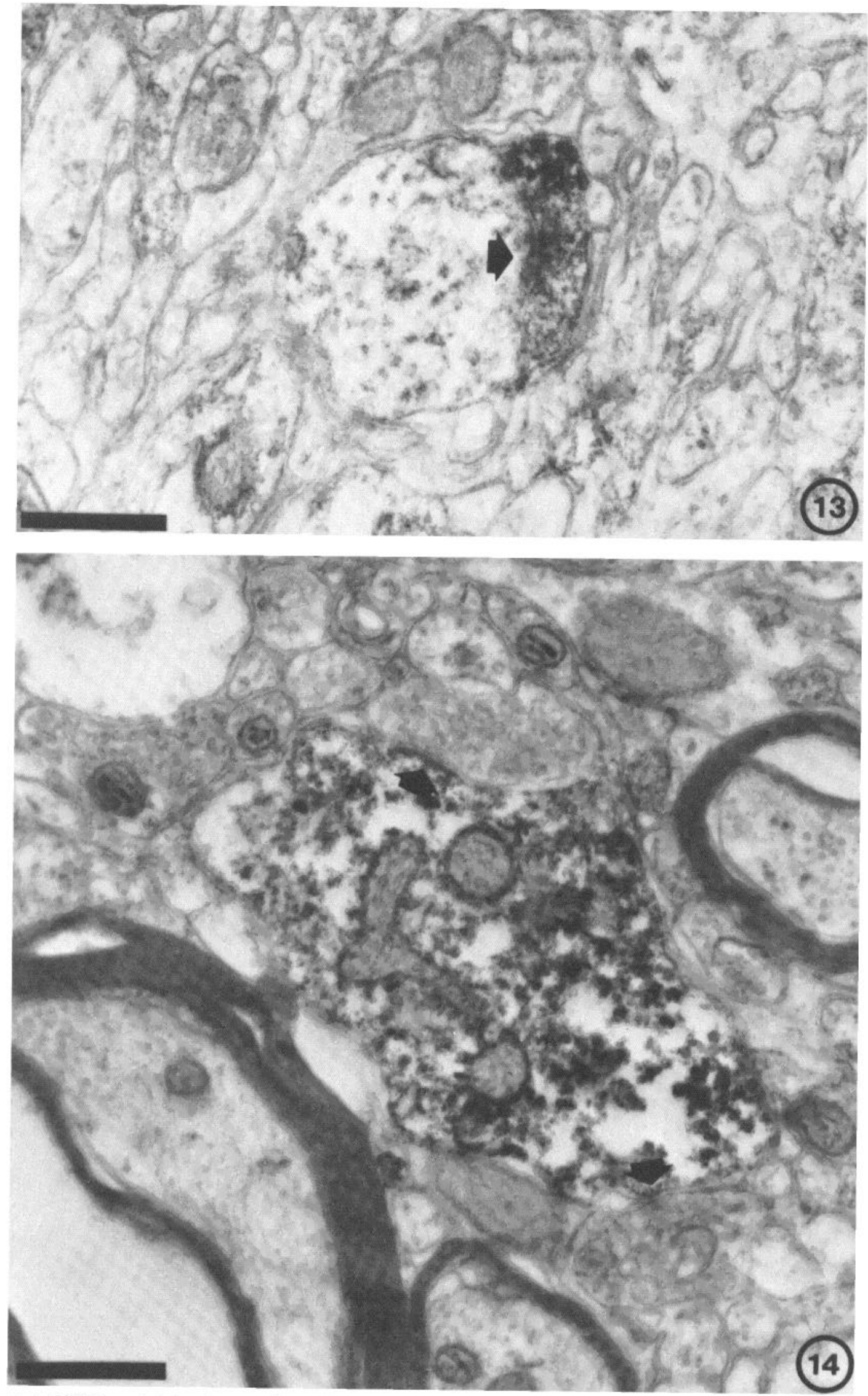

Figure 13. Labeled VIP-containing bouton from the dorsomedial aspect of the suprachiasmatic nucleus. The reaction product is located within and on the external surface of small spherical vesicles. In addition, the bouton forms an asymmetric synaptic axodendritic contact (arrow). Marker bar $=0.5 \mu \mathrm{m}$.

Figure 14. An immunoreactive dendrite in the ventral aspect of the SCN exhibits two sites of asymmetric synaptic contact (arrows) with unlabeled boutons containing flattened vesicles. Marker bar $=0.5 \mu \mathrm{m}$. 
14). 'To date, we have not observed synaptic contact between two immunoreactive profiles, and axosomatic contacts involving immunoreactive boutons are rare.

\section{Discussion}

The present immunocytochemical demonstration of vasoactive intestinal polypeptide-containing nerve cell perikarya and processes within the suprachiasmatic nuclei of the rat contributes to the increasing number of chemically defined cells and processes which have been identified within this hypothalamic nucleus. In addition to VIP, neurons have been localized within the SCN which exhibit positive immunocytochemical staining for vasopressin (Vandesande et al., 1975; Dierickx and Vandesande, 1977, 1979; Krisch, 1978; van Leeuwen et al., 1978; Sofroniew and Weindl, 1978, 1980; Weindl and Sofroniew, 1980), neurophysin (Zimmerman and Robinson, 1976; Sofroniew and Weindl, 1978; Peterson et al., 1980), and somatostatin (Parsons et al., 1976; Alpert et al., 1976; Dierickx and Vandesande, 1979). Similarly, several different chemically defined axonal populations have been demonstrated within the suprachiasmatic nuclei by means of immunocytochemistry, autoradiography, and fluorescence histochemistry. These include dense fiber plexuses of vasopressin/neurophysin (Vandesande et al., 1975; van Leeuwen et al., 1978; G. M. Peterson, W. B. Watkins, and R. Y. Moore, unpublished observations), somatostatin (Hökfelt et al., 1978), serotonin (Fuxe, 1965a, b; Aghajanian et al., 1969; Moore et al., 1978; Nojyo and Sano, 1978; Ajika and Ochi, 1978), and avian pancreatic polypeptide (J. P. Card, N. Brecha, and R. Y. Moore, unpublished observations), as well as scattered substance $\mathrm{P}$ and thyrotropin-releasing-hormone-containing processes (see Hökfelt et al., 1978, for review). From the results of the above mentioned immunocytochemical investigations and recent light and electron microscopic analyses (van den Pol, 1980; Moore et al., 1980), it has become increasingly evident that the suprachiasmatic nuclei are composed of distinct subdivisions in which the cells are morphologically and chemically distinct. This is particularly evident in the immunocytochemical characterization of cell types reported in this and other studies. A number of investigations have reported vasopressin-containing neurons which are located preferentially within the dorsal and medial aspect of the SCN. While previous reports (Sofroniew and Weindl, 1978, 1980) indicated that this neuronal population was relegated to the rostral half of the SCN, recent evidence (G. M. Peterson, W. B. Watkins, and R. Y. Moore, unpublished observations; J. P. Card, N. Brecha, and R. Y. Moore, unpublished observations) obtained from immunocytochemical staining for either neurophysin or vasopressin indicate that this group of cells occurs throughout the rostrocaudal extent of the SCN. Dierickx and Vandesande (1979) have provided evidence that neurons in the dorsomedial segment of the SCN can be subdivided further on the basis of their immunocytochemical staining characteristics. Using double labeling immunocytochemical procedures, these authors demonstrated that somatostatin and vasopressin are contained in separate neurons in the dorsomedial aspect of the SCN. No indication was given as to the rostrocaudal distribution of somatostatin neurons in their study. Evidence for further subdivision of suprachiasmatic neurons is presented in the present investigation and that of Sims et al. (1980). Sims et al. (1980) reported that, in the rat and mouse, specific cell body staining for VIP was ohserved in the basal and caudal portions of the SCN. Our findings in the rat, while in basic agreement with Sims et al. (1980), differ somewhat in the rostrocaudal distribution of VIP-positive perikarya. In coronal, sagittal, and horizontal sections through the SCN, we observed positively stained perikarya concentrated within the ventral aspect of the medial two-thirds of the nucleus. The rostral and caudal poles of the SCN exhibited few, if any, positively stained neurons. This slight discrepancy might be explained by the difficulty that is often encountered in defining the boundaries of the SCN. Since the nucleus merges gradually with the adjacent hypothalamus along its peripheral aspects, often it is difficult to identify the dorsal and lateral borders of the SCN. We have attempted to circumvent this problem by staining sections adjacent to those processed for immunocytochemistry with cresyl violet and are confident, after examining a number of different cases in various planes of section, that the rostral and caudal poles of the SCN contain only scattered VIP-positive perikarya.

The possibility that the chemically distinct classes of neurons also may be segregated on the basis of morphology is supported by the electron microscopic findings of the present investigation. Our findings indicate that the VIP-positive neurons in the ventral portion of the SCN are characterized by a spherical to slightly elongated cell soma containing a centrally placed nucleus which often exhibits a number of irregular invaginations. The cytoplasm of these cells exhibits a light organelle-rich matrix. By contrast, perikarya present in the dorsomedial portion of the nucleus are characterized by an elongated cellular conformation, with the nucleus filling most of the soma. The organelle-poor cytoplasm forms a thin rim around the nucleus in the short axis of the cell and the few organelles present accumulate in the cytoplasm at each pole of the neuron. These findings correlate well with those reported in recent light and electron microscopic studies of the cellular morphology of neurons in the adult rat suprachiasmatic nuclei (van den Pol, 1980; Moore et al., 1980). Each of these investigations indicated that the SCN can be subdivided into dorsomedial and ventrolateral segments on the basis of differences in cell morphology. In both of these studies, the general morphology of neurons in each of the designated SCN subfields corresponds closely to that described for the VIP neurons in the ventral SCN and the unstained neuronal perikarya in the dorsomedial segment of the SCN in the present study. Since the majority of neurons in the dorsomedial segment of the SCN have been shown to contain vasopressin (VP) or its carrier protein neurophysin, it would appear that VP and VIP cell groups differ in cell morphology as well as histochemical staining characteristics and distribution within the nucleus.

Parcellation of the suprachiasmatic nucleus is also evident in the pattern of termination of SCN afferents. Regional patterns of innervalion within the SCN have been demonstrated for optic boutons (Moore and Lenn, 
1972; Hendrickson et al., 1972; Moore, 1973; Mai and Junger, 1977; Güldner, 1978a, b), serotonergic axons (Fuxe, 1965a, b; Aghajanian et al., 1969; Moore et al., 1978; Ajika and Ochi, 1978), avian pancreatic polypeptide-containing axons (J. P. Card, N. Brecha, and R. Y. Moore, unpublished observation), and axons arising from the ventral lateral geniculate nucleus (Swanson et al., 1974; Ribak and Peters, 1975). Other SCN axonal plexuses, which differ in that they arise primarily from neurons in the SCN, seem less subject to the strict parcellation which is characteristic of the retinal, serotonergic, avian pancreatic polypeptide, and geniculate afferents. This is illustrated by the distribution of vasopressin and VIP axons in the SCN. Each of these fiber systems arises from neurons situated within the confines of the SCN and both plexuses are distributed throughout the nucleus. In addition, the electron microscopic findings of the present investigation illustrate VIP-containing boutons establishing classical asymmetric synaptic contacts with SCN dendrites. These findings would seem to suggest that, while afferent input to specific subfields of the SCN may serve to influence only selected groups of neurons in the nucleus, VP and VIP axons may, through their intranucleus arborization, integrate the activity of various subpopulations of SCN neurons.

Our study, although primarily concerned with the distribution of VIP axons within or in close proximity to the SCN, does provide some information on efferent projections of VIP-containing SCN neurons to other hypothalamic areas. A large number of beaded VIP axons can be traced from the dorsal aspect of the suprachiasmatic nuclei into the ipsilateral periventricular hypothalamic nucleus and through it to the ventral border of the paraventricular hypothalamic nucleus (PVH) where they form an extensive arborization of varicose axons along the ventral border of the PVH. This finding is consistent with the autoradiographic study of Swanson and Cowan (1975). Following an injection of tritiated proline that appeared to be isolated to the ventral portion of the SCN, these authors reported considerable accumulation of silver grains along the ventral and medial borders of the PVH. This finding has been confirmed subsequently by Berk and Finkelstein (1980) following iontophoretic injection of tritiated leucine into the SCN. It therefore appears that at least a portion of this projection is composed of axons arising from VIP neurons of the SCN. Our study also demonstrated a large number of varicose axons coursing horizontally between the two suprachiasmatic nuclei. Such fibers also were reported by Sims et al. (1980) in their study of VIP localization in the SCN, and Moore et al. (1979) observed labeled cells in the contralateral SCN following iontophoretic injections of horseradish peroxidase which were confined totally to the injected nucleus.

The functional significance of the demonstrated chemically and morphologically distinct SCN subdivisions remains to be determined. Numerous studies have indicated that the suprachiasmatic nuclei function as a circadian oscillator in the rat brain. However, to date, there is no conclusive evidence to suggest a separation of circadian functions among any of the demonstrated subdivisions of the nucleus. Peterson et al. (1980) analyzed circadian rhythmicity of locomotor activity, drinking behavior, and pineal serotonin $N$-acetyltransferase levels in female Brattleboro rats genetically deficient in vasopressin and found no disruption in any rhythm studied. Thus, it is evident that vasopressin-containing neurons, which are the principal cell type in the dorsomedial aspect of the SCN, are not essential for the maintenance of these rhythms in the rat. Mosko and Moore $(1978,1979)$ analyzed circadian rhythms in spontaneous locomotor activity and drinking behavior following total and partial ablation of the SCN of the neonate. Their findings demonstrated a total loss of rhythmic function of these parameters in animals which received a complete ablation of the SCN. Incomplete lesions in which various portions of the SCN were left intact spared some of the circadian function, but there was no clear evidence to indicate any association between any separate function and a specific subfield within the nucleus. Indeed, extensive investigations (Raisman and Brown-Grant, 1977; van den Pol and Powley, 1979) of the effects of the partial and total SCN ablation in the rat suggest equipotentiality rather than localization of function in the nucleus. Nevertheless, resolution of this question requires more detailed analysis of the fine stuctural organization of different areas of the SCN as well as the behavioral consequences of discrete lesions of specific cell and fiber populations in the SCN.

Determination of the importance of VIP and other peptides in the function of the SCN depends upon a clear definition of their role in synaptic transmission. A number of investigations have shown that VIP fulfills several of the criteria which are necessary prerequisites for consideration as a neurotransmitter (See Fahrenkrug, 1979, for review). VIP has been demonstrated within both neurons and vesicles of nerve terminals. Other investigations have demonstrated potassium-evoked calciumdependent release from hypothalamic nerve terminals as well as binding to specific central nervous system receptors. In addition, we have demonstrated that VIP is contained within terminals in the SCN which form classical asymmetric synaptic contacts with dendrites. While a number of criteria remain to be satisfied before VIP is accepted as a neurotransmitter in the central nervous system, its high concentration in SCN neurons and processes indicates that this cell and process system should be considered in any future morphological or functional investigation of this hypothalamic nucleus.

\section{References}

Adams, J. C. (1977) Technical considerations on the use of horseradish peroxidase as a neuronal marker. Neuroscience 2: 141-145.

Aghajanian, G. K., F. E. Bloom, and M. H. Sheard (1969) Electron microscopy of degeneration within the serotonin pathway of the rat brain. Brain Res. 13: 266-273.

Ajika, A., and J. Ochi (1978) Serotonergic projections to the suprachiasmatic nucleus and median eminence of the rat: Identification by fluorescence and electron microscopy. J. Anat. 127: 563-576.

Alpert, L. C., J. R. Brawer, Y. C. Patel, and S. Reichlin (1976) Somatostatinergic neurons in anterior hypothalamus: Immunohistochemical localization. Endocrinology 98: 255-258.

Barry, J., M. -P. DuBois, and B. Carette (1974) Immunofluorescence study of the preoptic-infundibular LRF neurosecre- 
tory pathway in the normal, castrated or testosterone-treated male guinea pig. Endocrinology 95: 1416-1423.

Berk, M. L., and J. A. Finkelstein (1980) An autoradiographic analysis of the efferent connections of the suprachiasmatic nucleus. Soc. Neurosci. Abstr. 6: 521.

Coons, A. H. (1958) Fluorescent antibody methods. In General Cytochemical Methods, J. F. Danielli, ed., pp. 399-422, Academic Press, New York.

Dierickx, K., and F. Vandesande (1977) Immunocytochemical localization of the vasopressinergic and the oxytocinergic neurons in the human hypothalamus. Cell Tissue Res. 184: $15-27$.

Dierickx, K., and F. Vandesande (1979) Immunocytochemical localization of somatostatin-containing neurons in the rat hypothalamus. Cell Tissue Res. 201: 349-359.

Fahrenkrug, J. (1979) Vasoactive intestinal polypeptide: Measurement, distribution and putative neurotransmitter function. Digestion 19: 149-169.

Fuxe, K. (1965a) The distribution of monoamine terminals in the central nervous system. Acta Physiol. Scand. (Suppl.) 247: $37-85$.

Fuxe, K. (1965b) Evidence for the existence of monoamine neurons in the central nervous system. IV. Distribution of monoamine nerve terminals in the central nervous system. Acta Physiol. Scand. (Suppl.) 247: 39-85.

Fuxe, K., T. Hökfelt, S. Said, and V. Mutt (1977) Evidence for the existence of VIP containing nerve terminals in the rat brain. Neurosci. Lett. 5: 241-246.

Güldner, F. H. (1978a) Synapses of optic nerve afferents in the rat suprachiasmatic nucleus: I. Identification, qualitative description, development and distribution. Cell Tissue Res. 194: 17-35.

Güldner, F. H. (1978b) Synapses of optic nerve afferents in the rat suprachiasmatic nucleus. II. Structural variability as revealed by morphometric examination. Cell Tissue Res. 194: $37-54$.

Hendrickson, A. E., N. Wagoner, and W. M. Cowan (1972) An autoradiographic and electron microscopic study of retinohypothalamic connections. Z. Zellforsch. Mikrosk. Anat. 135: $1-26$.

Hökfelt, T., R. Elde, K. Fuxe, O. Johansson, A. Ljungdahl, M. Goldstein, R. Luft, S. Efendic, G. Nilsson, L. Terenius, D. Ganten, S. L. Jeffcoate, J. Rehfeld, S. Said, M. Perez de la Mora, L. Possani, R. Tapia, L. Teran, and R. Palacios (1978) Aminergic and peptidergic pathways in the nervous system with special reference to the hypothalamus. In The Hypothalamus, S. Reichlin, K. J. Baldessarini, and J. B. Martin, eds., pp. 69-134, Raven Press, New York.

Krisch, B. (1978) Light and electron microscopic localization of vasopressin or vasopressin-like substance in neurons of the rat SCN. Cell Tissue Res. 194: 361-365.

Langford, L. A., and R. E. Coggeshall (1980) The use of potassium ferricyanide in neural fixation. Anat. Rec. 197: 297-303.

Mai, J. K., and E. Junger (1977) Quantitative autoradiographic light and electron microscopic studies on the retinohypothalamic connections in the rat. Cell Tissue Res. 183: 221-237.

McLean, I. W., and P. K. Nakane (1974) Periodate-lysine-paraformaldehyde fixative: A new fixative for immunoelectron microscopy. J. Histochem. Cytochem. 22: 1077-1083.

Moore, R. Y. (1973) Retinohypothalamic projection in mammals: A comparative study. Brain Res. 49: 403-409.

Moore, R. Y. (1979) The retinohypothalamic tract, suprachiasmatic hypothalamic nucleus and central mechanisms of circadian rhythm regulation. In Biological Rhythms and Their Central Mechanism, M. Suda, O. Hayaishi, and H. Hakagawa, eds., pp. 343-354, Elsevier/North-Holland Biomedical Press, Amsterdam.
Moore, R. Y., and N. J. Lenn (1972) A retinohypothalamic projection in the rat. J. Comp. Neurol. 146: 1-14.

Moore, R. Y., A. E. Halaris, and B. E. Jones (1978) Serotonin neurons of the midbrain raphe: Ascending projections. J. Comp. Neurol. 180: 417-438.

Moore, R. Y., E. R. Marchand, and J. N. Riley (1979) Suprachiasmatic nucleus afferents in the rat: An HRP-retrograde transport study. Neuroscience 5: 232.

Moore, R. Y., J. P. Card, and J. N. Riley (1980) The suprachiasmatic hypothalamic nucleus: Neuronal ultrastructure. Soc. Neurosci. Abstr. 6: 758.

Mosko, S., and R. Y. Moore (1978) Neonatal suprachiasmatic nucleus ablation: Absence of functional and morphological plasticity. Proc. Natl. Acad. Sci. U. S. A. 75: 6243-6246.

Mosko, S., and R. Y. Moore (1979) Retinohypothalamic tract development: Alteration by suprachiasmatic lesions in the neonatal rat. Brain Res. 164: 1-15.

Nojyo, Y., and Y. Sano (1978) Ultrastructure of the serotonergic nerve terminals in the suprachiasmatic and interpeduncular nuclei of rat brains. Brain Res. 149: 482-488.

Parsons, J. A., S. I. Frlandsen, O. D. Hegre, R. C. McEvoy, and R. P. Elde (1976) Central and peripheral localization of somatostatin immunoenzyme immunocytochemical studies. J. Histochem. Cytochem. 24: 872-882.

Peterson, G. M., W. B. Watkins, and R. Y. Moore (1980) The suprachiasmatic hypothalamic nuclei of the rat. VI. Vasopressin neurons and circadian rhythmicity. Behav. Neural Biol. 29: 236-245.

Pickel, V. M., K. K. Sumal, S. C. Beckley, R. J. Miller, and D. J. Reis (1980) Immunocytochemical localization of enkephalin in the neostriatum of rat brain: A light and electron microscopic study. J. Comp. Neurol. 189: 721-740.

Raisman, G., and K. Brown-Grant (1977) The suprachiasmatic syndrome, endocrine and behavioral abnormalities following lesions of the suprachiasmatic nuclei in the female rat. Proc. R. Soc. Lond. (Biol.) 198: 297-314.

Ribak, C. E., and A. Peters (1975) An autoradiographic study of the projections from the lateral geniculate body of the rat. Brain Res. 92: 341-368.

Sims, K. B., D. L. Hoffman, S. I. Said, and E. A. Zimmerman (1980) Vasoactive intestinal polypeptide (VIP) in mouse and rat brain: An immunocytochemical study. Brain Res. 186: $165-183$.

Sofroniew, M. V., and A. Weindl (1978) Projections form the parvocellular vasopressin and neurophysin-containing neurons of the suprachiasmatic nucleus. Am. J. Anat. 153: 391430.

Sofroniew, M. V., and A. Weindl (1980) Identification of parvocellular vasopressin and neurophysin neurons in the suprachiasmatic nucleus of a variety of mammals including primates. J. Comp. Neurol. 193: 659-677.

Sternberger, L. A. (1979) Immunohistochemistry, PrenticeHall, Englewood Cliffs, NJ.

Suburo, A. M., and A. Pellegrino de Iraldi (1969) An ultrastructural study of the rat's suprachiasmatic nucleus. J. Anat. 105: 439-446.

Swanson, L. W., and W. M. Cowan (1975) The efferent connections of the suprachiasmatic nucleus of the hypothalamus. J. Comp. Neurol. 160: 1-12.

Swanson, L. W., W. M. Cowan, and E. G. Jones (1974) An autoradiographic study of the efferent connections of the ventral lateral geniculate nucleus in the albino rat and the cat. J. Comp. Neurol. 156: 143-164.

van den Pol, A. N. (1980) The hypothalamic suprachiasmatic nucleus of the rat: Intrinsic anatomy. J. Comp. Neurol. 191: 661-702.

van den Pol, A., and T. Powley (1979) A fine-grained anatomical 
analysis of the role of the rat suprachiasmatic nucleus in circadian rhythms of feeding and drinking. Brain Res. 160: 307-326.

van Leeuwen, F. W., D. F. Swaab, and C. de Raay (1978) Immunoelectron localization of vasopressin in the rat suprachiasmatic nucleus. Cell Tissue Res. 193: 1-10.

Vandesande, F., K. Dierickx, and J. DeMey (1975) Identification of the vasopressin-neurophysin producing neurons of the rat suprachiasmatic nuclei. Cell Tissue Res. 156: 377-380.
Weindl; A., and M. V. Sofroniew (1980) Immunohistochemical localization of hypothalamic peptide-hormones in neural target areas. In Brain and Pituitary Peptides, W. Wuttke, A. Weindl, K. Voight, and R. R. Dries, eds., pp. 97-109, S. Karger, Basel.

Zimmerman, E. A., and A. G. Robinson (1976) Hypothalamic neurons secreting vasopressin and neurophysin. Kidney Int. 10: $12-24$. 